\title{
Ultrasound as a safe and reliable guidance for subarachnoid puncture in rabbits ${ }^{1}$
}

Ivan Dias Fernandes Pereira', Roberto Bezerra Vital", Ronaldo Silva", Felipe Gilberto Valerini"', Vania Maria de Vasconcelos Machado'v , Mariangela Esrher Marques`, Helio Miot ${ }^{\mathrm{V}}$, Lais Helena Navarro ${ }^{\mathrm{VII}}$, Eliana Marisa Ganem ${ }^{\text {III }}$

'PhD, Department of Anesthesiology, Universidade Estadual Paulista (UNESP), Botucatu-SP, Brazil. Conception and design of the study.

"Fellow PhD degree, Postgraduate Program in Anesthesiology, Department of Anesthesiology, UNESP, Botucatu-SP, Brazil. Statistical analysis, critical revision.

"'Graduate student, Botucatu Medical School, UNESP, Botucatu-SP, Brazil. Acquisition of data, technical procedures.

IVPhD, Assistant Professor, Department of Animal Reproduction and Veterinary Radiology, UNESP, Botucatu-SP, Brazil. Acquisition of data, technical procedures.

${ }^{\vee} \mathrm{PhD}$, Associate Professor, Department of Pathology, UNESP, Botucatu-SP, Brazil. Histopathological examinations.

VIPhD, Assistant Professor, Department of Dermatology, UNESP, Botucatu-SP, Brazil. Statistical analysis.

VIIPhD, Assistant Professor, Department of Anesthesiology, UNESP, Botucatu-SP, Brazil. Critical revision.

VIIIPhD, Full Professor, Department of Anesthesiology, UNESP, Botucatu-SP, Brazil. Intellectual and scientific content of the study, manuscript writing, critical revision.

\section{Abstract}

Purpose: To evaluate a model for studying the toxicity in nervous tissue and meninges using ultrasound to guide needle insertion into the subarachnoid space of rabbits, with the objective of avoiding injuries triggered by the puncture and by intraneural injection of solutions.

Methods: Forty-five adult female rabbits were divided into 3 groups (G): $G 1$ underwent subarachnoid puncture, G2 underwent subarachnoid injection of saline solution and G3 underwent subarachnoid injection of $0.5 \%$ hyperbaric bupivacaine. A needle was inserted into the S1-S2 subarachnoid space guided by ultrasound. The sensitivity and motility of the animals were evaluated for 3 days, after which the animals were sacrificed for removal of lumbar and sacral portions of the spinal cord for histological examination by light microscopy and immunohistochemistry.

Results: All animals had motor function and pain sensitivity on the evaluation period. No animal had complication during or after the procedures.

Conclusion: Ultrasound is a useful and safe method for the correct identification of the subarachnoid space of rabbits.

Key words: Neurotoxicity. Anesthesia, Spinal. Ultrasonography. Rabbits. 


\section{Introduction}

Neurological complications following neuraxial blockade are rare but potentially serious. Such complications can cause irreversible adverse effects to the meninges, the nervous tissue of the spinal cord and the roots of the cauda equina ${ }^{1,2}$. Many animal models are used to study neurotoxicity, and in the majority of the studies using rabbit models, the drug was introduced into the subarachnoid space through a chronically implanted catheter $^{3-12}$. In some studies, inflammatory cells were observed in the meninges ${ }^{3,6}$ and in the nervous tissue ${ }^{3}$ surrounding the catheter. Neuroimmune alterations that manifested as increased glial markers and expression of specific cytokines were also observed ${ }^{13}$.

Experimental studies that employ intrathecal administration of solutions through single subarachnoid injection are those whose approach most resembles the anesthetic procedures used in clinical practice. The conventional method of nerve localization uses anatomical landmarks and nerve stimulation, which presents a high risk of nerve trauma. The use of ultrasound (US) imaging for regional anesthesia (RA) is steadily increasing: its advantages over conventional techniques are significant, since it allows direct ultrasonographic guidance of the needle to the selected nerve zone ${ }^{14-16}$.

We sought to establish a model for studying the toxicity in nervous tissue and meninges using ultrasound to guide needle insertion into the subarachnoid space of rabbits, confirming this as a reliable method.

\section{- Methods}

After proper approval by the Botucatu Medical School Ethics Committee on animal experiments, 45 adult female rabbits were obtained from the Experimental Animal
Center-UNESP, Botucatu Campus. The animals weighed between 3500 and $4500 \mathrm{~g}$, and their spine lengths ranged between 35 and $38 \mathrm{~cm}$. All tests were performed in accordance with the guidelines of the International Association for the Study of Pain ${ }^{17}$.

Using a list of computer-generated random numbers, animals were randomly allocated into three groups (G), containing 15 animals each. Group 1 (G1) was subjected to subarachnoid puncture to evaluate if this technique causes any puncture accident. Group 2 (G2) received a subarachnoid injection containing $0.9 \%$ saline solution to evaluate the effects of such volume of solution on the nervous tissue. Group 3 (G3) received hyperbaric $0.5 \%$ (Cristália pharmaceutical laboratory) to evaluate the effects of the drug on the nervous tissue.

Animals that appeared unhealthy, needed more than one subarachnoid puncture or had hemorrhagic cerebrospinal fluid (CSF) (i.e., from a puncture accident) were excluded from the study. No animal had to be excluded in this study.

\section{Anesthesia and animal preparation}

After a 12-hour fasting period with free access to water. The animals were weighed and anesthetized with intravenous injection of xylazine chlorhydrate ( $3 \mathrm{mg} \mathrm{kg}^{-1}$ body weight) and ketamine chlorhydrate $\left(10 \mathrm{mg} \cdot \mathrm{kg}^{-1}\right.$ body weight).

After intravenous anesthesia, the animals were placed in the prone position with the back paws extended under the abdomen. The length of the spinal cord was measured from the base of the skull to the sacral area.

The animal's skin and fur in the spinal column area were cleaned with soap and water. A $10 \mathrm{~cm}$ area, corresponding to the S1-S2 intervertebral space, was shaved and washed with $0.9 \%$ saline solution. The naked skin was submitted to antisepsis with a $2 \%$ 
chlorhexidine gluconate solution, and sterile fields were appropriately positioned.

\section{Subarachnoid puncture and clinical evaluation}

Each rabbit's subarachnoid space was accessed through the S1-S2 intervertebral space, which was the most caudal space that allowed the puncture. This intervertebral space was identified through the palpation of the two tuberosities of the pelvic bone and the spinous process of the first sacral vertebra, sliding the finger 1.5 to $2 \mathrm{~cm}$ in the caudal direction. The S1-S2 space is located $1 \mathrm{~cm}$ caudal to the spinous process of the first sacral vertebra ${ }^{18}$.

The subarachnoid block was guided by ultrasound using the SonoSite apparatus (USA), model M-Turbo, which includes tissue Doppler imaging (TDI) and a micro-linear transducer with a frequency of 10.0 to $13 \mathrm{MHz}$.

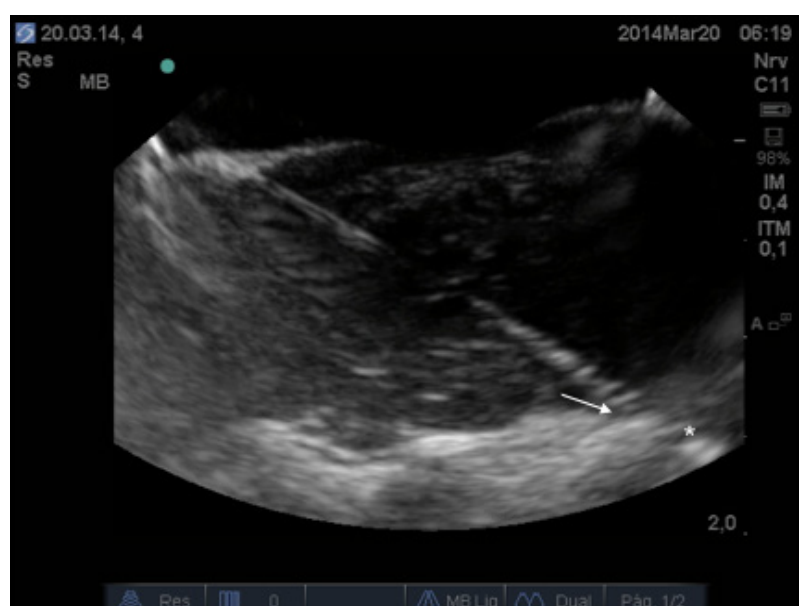

Figure 1 - Ultrasound-guided image on sagittal approach of S1-S2 joint space was obtained using a 10-13 MHZ micro-convex transducer. The needle was inserted in the space of S1-S2 (arrow), the sacral vertebrae is hiperecoic and subarachnoid space is hipoecoic (asterisk).

Subarachnoid puncture was performed with a Quincke spinal needle, 22G 1 1/2", by median approach, with a tilt angle of approximately $45^{\circ}$, the needle was slowly introduced in the cephalic direction until it penetrated the yellow ligament. At this point, there is a change in the resistance and with the help of ultrasound, the correct positioning of the needle in subarachnoid space is obtained (Figure 1). Animals in G1 received no solution (control puncture), while G2 and G3 animals received the appropriate solutions corresponding to $5 \mu \mathrm{l}$ per $\mathrm{cm}$ of spinal cord $(0.2$ $\mathrm{ml}$ ). These solutions were injected within 1 second with a $1 \mathrm{ml}$ disposable syringe.

The animals were evaluated clinically for 3 days as to motor block and pain nociception. Motor block was assessed by clinical observation and was classified according to the criteria established by Drummond and Moore ${ }^{19}$ as follows: 3- free movement of the lower extremities; 2 - asymmetry and limitation to support the body and to ambulate due to changes in the lower extremities; 1 - inability to support the body with the lower extremities; 0 - paralysis of the lower extremities.

Nociception was assessed by reaction to painful pressure stimuli, elicited by the bilateral pinch of a skin fold over sacral, lumbar, and thoracic dermatomes, as well as the interdigital membranes of limbs and ears, by a surgical clamp. The presence of pain was defined by the following: limb withdrawal, vocalization, and facial expression. Nociception was classified dichotomously into absent or present.

\section{Spinal cord preparation and staining}

Histological analysis of the spinal cord and meninges of the rabbits was performed after the 21-day observation period. To obtain tissue samples, animals were first given a sodium pentobarbital IV then euthanized by decapitation. Thereafter, the lumbar and sacral segments of the spinal cord with the surrounding meninges were quickly removed within 3 minutes to minimize the risk of injuries to those tissues from ischemia and apoptosis. The anatomical pieces were fixed in a $10 \%$ 
formalin solution. After a 7-day incubation period, $0.5 \mathrm{~cm}$ thick histological sections were prepared starting $10 \mathrm{~cm}$ above the level of the spinal puncture to the end of the cauda equina. The histological sections were stained by hematoxylin and eosin (H\&E) and glial fibrillary acidic protein (GFAP) techniques and examined by optical microscopy. Two researchers (EMG and MAM), experienced in histological neurotoxicity assessment, unanimously classified each of the sections according to the presence or absence of histological injury. If any kind of lesion was identified, it was further specified. To investigate the possible dose- related gradient effect, injuries were stratified according to severity and extent as ascertained by consensus. Researchers blinded to the experimental groups performed all clinical and histological evaluations.

The results obtained by analysis of the nervous tissue and the meninges stained with H\&E were classified as normal when no alterations or injuries were observed. The type, location, extent and depth of the lesion were determined according to the following criteria (Table 1), also by In the presence of adhesive arachnoiditis (Table 2) and by presence of nerve injury

Table 1 - Criteria for lesions.

\begin{tabular}{|c|c|c|c|c|}
\hline Type of lesion & Arachnoiditis & Arachnoiditis + Nerve damage & Nerve damage & \\
\hline $\begin{array}{l}\text { Location of the } \\
\text { lesion }\end{array}$ & $\begin{array}{l}\text { Posterior } \\
\text { Region (P) }\end{array}$ & Lateral Region (L) & Anterior Region (A) & $\mathrm{P}+\mathrm{L}$ \\
\hline Lesion extent & $<10 \%$ & $10-50 \%$ & $>50 \%$ & \\
\hline $\begin{array}{l}\text { Depth of the } \\
\text { lesion }\end{array}$ & $\begin{array}{l}\text { White } \\
\text { Matter }\end{array}$ & Grey Matter & $\begin{array}{c}\text { White and Gray } \\
\text { Matter }\end{array}$ & \\
\hline Blood vessel & Normal & Fibrous Thickening & Thrombosis & \\
\hline
\end{tabular}

Table 2 - Adhesive arachnoiditis.

\begin{tabular}{lcccc}
\hline Adherence & Absent & Dura mater $(D)+$ Arachnoid $(A)$ & $A+$ Pia Mater & $D+A+P$ \\
\hline $\begin{array}{l}\text { Thickening of the } \\
\text { meninges }\end{array}$ & Absent & Mild & Moderate & Intense \\
\hline Lymphocytic infiltrate & Absent & Mild & Moderate & Intense \\
\hline Fibrosis & Absent & Mild & Moderate & Intense \\
\hline
\end{tabular}

The cellular marker percentage was estimated based on the immunohistological assessment of the area marked by the GFAP in the dorsal horn of the spinal cord for thorough examination of marrow cellularity. For this assessment, the histological sections stained with GFAP were photographed then subjected to digital processing using the software Image J
1.46 and the plugin "Color Deconvolution".

A rectangular area of the tissue was selected, and the contrast was increased in a standard manner for binarization of the image. The area percentages of pixels equivalent to the tissue marked by DAB (Figure $2 A-B$ ) were evaluated and compared among groups ${ }^{20-23}$. 


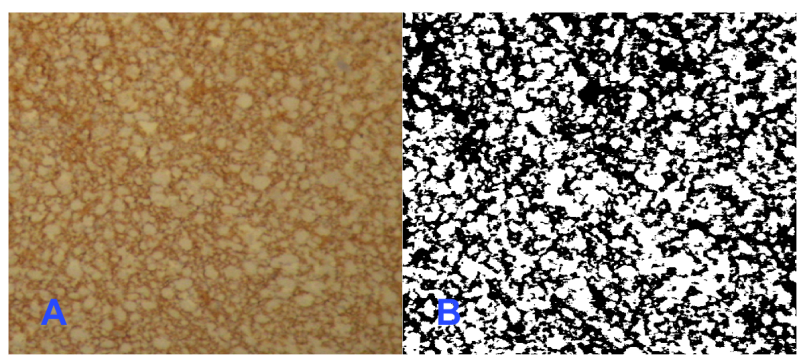

Figure 2 - A. Selected area of neural tissue. B. Binarized area after image processing, resulting in marking of $45 \%$ of the tissue.

\section{Statistical analysis}

Assuming an estimated nervous tissue injury rate of $70 \%{ }^{24}$ and an induced rate of $1 \%$ for the saline solution, for an $\alpha$ significance level of $5 \%$ (limit of detection for type I errors) and $95 \%$ power, fifteen animals per group were enough.

Analysis of variance (ANOVA) was used to evaluate the homogeneity of the groups with respect to weight, length of the spine and volume of solution administered in the subarachnoid space (results are expressed as the means and standard deviations). The nonparametric Mann-Whitney test was used to compare the results of the GFAP immunohistochemical staining (results are presented as medians and first and third quartiles), with $\mathrm{p}<0.05$ values considered significant.

\section{- Results}

Of the 45 animals selected, none was excluded from the study. All had healthy appearances, and there was no need for more than one puncture. The position of the rabbits on the surgical table hampered the CSF flow because the needle was in a horizontal position relative to the table. Hence, reflux through the needle was only observed in one G1 animal and three $\mathrm{G} 3$ animals.
No G1 and G2 animals showed evidence of motor or sensory block after recovering from the intravenous anesthesia. While under the effects of the local anesthetic, all G3 animals showed sensory block in the lower extremities or sacral region and motor block of varying degrees: three rabbits showed grade 0 block paralysis of the lower extremities; five animals had grade1 block - inability to support the body and lower extremities; and seven rabbits had grade 2 block - asymmetry of the ability to support the body with the lower extremities. After reversal of the subarachnoid block, the $\mathrm{G} 3$ animals regained motor function and pain sensitivity. No rabbits in any of the three groups showed sensory or motor alterations during the three days that they remained under clinical observation.

The histological sections of nervous tissue and meninges were normal in the fortyfive animals. The blood vessels and meninges were normal in all rabbits.

In only one animal of $\mathrm{G} 1$ was difficult to visualize the structures by ultrasound; repositioning the probe solved this problem.

Statistical analysis revealed homogeneity among groups for weight ( $p=$ $0.75)$, length of the spine ( $p=0.85)$, volume of solution injected into the subarachnoid space $(p=0.86)$ and percentage of tissue by marked $\operatorname{GFAP}(p=0.42)$.

\section{- Discussion}

It has long been known that the trauma triggered by the introduction of the needle into the fascicles triggers severe neuronal damage to the peripheral nerves of rabbits $^{25}$. Intraneuronal rupture, distal axonal degeneration and disorganized regeneration of nerve fibers have been reported after the introduction of a needle into the peripheral nerves of rats ${ }^{26}$.

In this study, no lesions were observed 
in the nervous tissue or meninges of rabbits subjected to subarachnoid puncture (G1), which was performed with the objective of evaluating the safety of the technique. Considering that the puncture site contained spinal nervous tissue ${ }^{27}$, it was demonstrated that the needle, guided by ultrasound imaging, did not cause any injury to this tissue. G2 animals received saline solution via a subarachnoid route to study the effect of the volume of solution on the nervous tissue.

The subarachnoid space of the rabbit, where the puncture was performed (the most caudal site that allows the passage of the needle), is small and still contains spinal cord tissue ${ }^{27}$. Thus, it is imperative to rule out the possibility that the volume of solution administered could induce nerve injuries. The only small obstacle in this study was finding the appropriate position for the ultrasound probe that would not hinder the insertion of the needle in the skin and subcutaneous tissue.

Some authors have hypothesized that acute increases in the CSF volume may lead to increased CSF pressure, affecting the spinal cord blood flow and causing spinal cord ischemia and neurological lesions ${ }^{28}$. To investigate this possibility, $\mathrm{G} 2$ rabbits were also used to exclude any intraneural injection of the solution. The injection of $0.05 \mathrm{ml}$ of saline solution into the fascicles of the peripheral nerves of rabbits is sufficient to degenerate the axons ${ }^{25,26}$.

The laceration of nerve tissue, characterized by the presence of a linear strip of necrosis and hemorrhage from the periphery to the center of the medulla, could be observed after saline solution injection in rabbits ${ }^{29}$. This type of histologic lesion differs from that triggered by the toxicity of the local anesthetic solution, which may affect both superficial and deep areas of the nervous tissue ${ }^{18,29}$.

G3 animals received $0.5 \%$ hyperbaric bupivacaine to evaluate the effects of the drug on the nervous tissue. This local anesthetic has been administered to the subarachnoid spaces of sheep ${ }^{30}$ and dogs $s^{31}$ without triggering any neurotoxic lesions, which indicates that it is safe for use as a drug control. This group was important to ensure the correct positioning of the needle into the subarachnoid space, since all the animals in this group had sensory and motor block. If by chance the injection had been made in the epidural space, would not be possible as dense blocks.

As for the volume of solution injected into the subarachnoid space, a study using a calculation similar to our study showed via staining that a volume of five $\mu \mathrm{l} . \mathrm{cm}^{-1}$ was sufficient to cover the nervous tissue of the low thoracic, lumbar, sacral and caudal regions ${ }^{18}$. In the present study, blockade of pain sensitivity only reached the lumbar region.

Other authors who used larger volumes (0.02 ml. $\mathrm{cm}^{-1}$ of spine) observed that $50 \%$ of the animals had histological lesions at the site of puncture, which was performed in the lumbosacral space. The lesions were consistent with puncture trauma and were different from those triggered by the nervous tissue toxicity induced by the local anesthetic (i.e., swelling of the axon and myelin sheath, macrophage inflammatory infiltrates, axonal degeneration and the presence of vacuoles) ${ }^{29}$.

The advantage of using rabbits to study the toxicity of drugs in the subarachnoid space lies in their small volume of $\mathrm{CSF}^{32}$. This volume allows the solution to be only slightly diluted in the subarachnoid space; hence, its concentration in the nervous tissue is very similar to the administered concentration. The disadvantage is that the drug is not diluted in the CSF, as occurs in animals that have greater volumes of CSF.

\section{- Conclusions}

The use of ultrasound proved useful for providing the correct location of the subarachnoid space in rabbits, which enables its use in neurotoxicity studies. Correct positioning of the guided needle avoided trauma to vessels and nerve structures as well as intraneural injection of the solutions. 


\section{References}

1. Rice I, Wee MY, Thomson K. Obstetric epidurals and chronic adhesive arachnoiditis. $\mathrm{Br} J$ Anaesth. 2004;92(1):109-20. PMID: 14665562.

2. Vianna PT, Vane LA, Yong LC, Franco MF, Massone F. Morphological changes in the spinal cord of dogs undergoing hyperbaric injection with $1.2 \%$ tetracaine, $5 \%$ lidocaine and $10 \%$ glucose. Rev Bras Anestesiol. 1985;35(Suppl. 5):S1-6.

3. Borgbjerg FM, Svensson BA, Frigast C, Gordh T, Jr. Histopathology after repeated intrathecal injections of preservative-free ketamine in the rabbit: a light and electron microscopic examination. Anesth Analg. 1994;79(1):10511. PMID: 8010418.

4. Hashimoto K, Karasawa F, Satoh T. Intrathecal midazolam attenuates renal sympathetic nerve activity in rabbits. Masui. 1997;46(8):1059-65. PMID: 9283161.

5. Kaneko S, Matsumoto M, Tsuruta S, Hirata T, Gondo T, Sakabe T. The nerve root entry zone is highly vulnerable to intrathecal tetracaine in rabbits. Anesth Analg. 2005;101(1):10714. PMID: 15976215.

6. Malinovsky JM, Charles F, Baudrimont $M$, Pereon $\mathrm{Y}$, Le Corre $\mathrm{P}$, Pinaud $\mathrm{M}$, Benhamou D. Intrathecal ropivacaine in rabbits: pharmacodynamic and neurotoxicologic study. Anesthesiology. 2002;97(2):429-35. PMID: 12151934.

7. Saeki H, Matsumoto M, Kaneko S, Tsuruta S, Cui YJ, Ohtake K, Ishida K, Sakabe T. Is intrathecal magnesium sulfate safe and protective against ischemic spinal cord injury in rabbits? Anesth Analg. 2004;99(6):180512. PMID: 15562076.

8. Vranken JH, Troost D, de Haan P, Pennings FA, van der Vegt $\mathrm{MH}$, Dijkgraaf MG, Hollmann MW. Severe toxic damage to the rabbit spinal cord after intrathecal administration of preservative-free $\mathrm{S}(+)$-ketamine. Anesthesiology. 2006;105(4):813-8. PMID: 17006081.

9. Oka S, Matsumoto M, Ohtake K, Kiyoshima T, Nakakimura K, Sakabe T. The addition of epinephrine to tetracaine injected intrathecally sustains an increase in glutamate concentrations in the cerebrospinal fluid and worsens neuronal injury. Anesth Analg. 2001;93(4):1050-7. PMID: 11574382.

10.Wang BC, Hillman DE, Spielholz NI, Turndorf $H$. Chronic neurological deficits and Nesacaine-CE--an effect of the anesthetic, 2-chloroprocaine, or the antioxidant, sodium bisulfite? Anesth Analg. 1984;63(4):445-7. PMID: 6703372.

11.Yamashita A, Matsumoto $M$, Matsumoto $\mathrm{S}$, Itoh M, Kawai K, Sakabe T. A comparison of the neurotoxic effects on the spinal cord of tetracaine, lidocaine, bupivacaine, and ropivacaine administered intrathecally in rabbits. Anesth Analg. 2003;97(2):512-9. PMID: 12873946.

12.Demirel E, Ugur HC, Dolgun $H$, Kahilogullari G, Sargon ME, Egemen N, Kecik Y. The neurotoxic effects of intrathecal midazolam and neostigmine in rabbits. Anaesth Intensive Care. 2006;34(2):218-23. PMID: 16617644.

13.DeLeo JA, Colburn RW, Rickman AJ, Yeager MP. Intrathecal catheterization alone induces neuroimmune activation in the rat. Eur J Pain. 1997;1(2):115-22. PMID: 15102412.

14.Griffin J, Nicholls B. Ultrasound in regional anaesthesia. Anaesthesia. 2010;65 Suppl 1:112. PMID: 20377542.

15. Marhofer P, Willschke $\mathrm{H}$, Kettner S. Current concepts and future trends in ultrasoundguided regional anesthesia. Curr Opin Anaesthesiol. 2010;23(5):632-6. PMID: 20689408.

16. Marhofer P, Chan VW. Ultrasoundguided regional anesthesia: current concepts and future trends. Anesth Analg. 2007;104(5):1265-9. PMID: 17456684.

17.Zimmermann M. Ethical guidelines for investigations of experimental pain in conscious animals. Pain. 1983;16(2):109-10. PMID: 6877845.

18. Ready LB, Plumer MH, Haschke RH, Austin E, Sumi SM. Neurotoxicity of intrathecal local anesthetics in rabbits. Anesthesiology. 1985;63(4):364-70. PMID: 3839985.

19.Drummond JC, Moore SS. The influence of dextrose administration on neurologic outcome after temporary spinal cord 
ischemia in the rabbit. Anesthesiology. 1989;70(1):64-70. PMID: 2912317.

20.Abramoff MD, Magalhães PJ, Ram SJ. Image processing with ImageJ. Biophotonics Int. 2004;11:36-42.

21.Landini G. Colour deconvolution. 2010. Available in http://www.mecourse.com/ landinig/software/cdeconv/cdeconv.html.

22. Ruifrok AC, Johnston DA. Quantification of histochemical staining by color deconvolution. Anal Quant Cytol Histol. 2001;23(4):291-9. PMID: 11531144.

23.Collins TJ. ImageJ for microscopy. Biotechniques. 2007;43(1 Suppl):25-30. PMID: 17936939.

24.Okagawa SR, Marques M, Barros GAM, Ganem EM. Efeitos de concentrações crescentes de lidocaína hiperbárica, administradas no espaço subaracnóideo, sobre a medula espinhal e as meninges. Extudo experimental no cão. Rev Bras Anestesiol. 2006;56(3):253-62.

25.Selander D, Brattsand R, Lundborg G, Nordborg C, Olsson Y. Local anesthetics: importance of mode of application, concentration and adrenaline for the appearance of nerve lesions. An experimental study of axonal degeneration and barrier damage after intrafascicular injection or topical application of bupivacaine (Marcain). Acta Anaesthesiol Scand. 1979;23(2):127-36. PMID: 442943.

26.Rice AS, McMahon SB. Peripheral nerve injury caused by injection needles used in regional anaesthesia: influence of bevel configuration, studied in a rat model. $\mathrm{Br} \mathrm{J}$ Anaesth. 1992;69(5):433-8. PMID: 1467070.

27.Santos AL, Lima EM, Santana MIS. Length of spinal cord and topography of medular cone in rabbits (Oryctolaguscuniculus). Biosci J. 1999;15:45-62.

28. Rosen MA, Baysinger CL, Shnider SM, Dailey PA, Norton M, Curtis JD, Collins M, Davis RL. Evaluation of neurotoxicity after subarachnoid injection of large volumes of local anesthetic solutions. Anesth Analg. 1983;62(9):802-8. PMID: 6881568.

29.Adams HJ, Mastri AR, Eicholzer AW, Kilpatrick G. Morphologic effects of intrathecal etidocaine and tetracaine on the rabbit spinal cord. Anesth Analg. 1974;53(6):9048. PMID: 4479726.

30.Adams HJ, Mastri AR, Doherty D, Jr. Bupivacaine: morphological effects on spinal cords of cats and durations os spinal anesthesia in sheep. Pharmacol Res Commun. 1977;9(9):847-55. PMID: 609578.

31.Ganem EM, Vianna PT, Marques M, Castiglia YM, Vane LA. Neurotoxicity of subarachnoid hyperbaric bupivacaine in dogs. Reg Anesth. 1996;21(3):234-8. PMID: 8744666.

32.Bieter RN, Cunningham RW, Lenz AO, McNearney JJ. Threshold anesthetic and lethal concentration of certain spinal anesthetics in the rabbit. J Pharmacol Exp Ther. 1936;57:221-44.

\section{Correspondence:}

Ivan Dias Fernandes Pereira

Rua Jair do Couto Costa, 172/casa 06

87060-625 Maringá - PR Brasil

Tel.: (55 44)3259-2262

ivandias71@gmail.com

Conflict of interest: none

Financial source: FAPESP (grant \# 2009/54490-3)
Received: Sep 21, 2016

Review: Nov 23, 2016

Accepted: Dez 22, 2016
${ }^{1}$ Research performed at Department of Anesthesiology, Universidade Estadual Paulista (UNESP), Botucatu-SP, Brazil. 